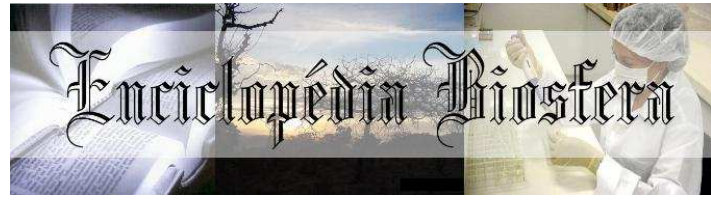

\title{
ANÁLISE TÉCNICA DE UM SISTEMA DE COLHEITA MECANIZADA DE TORAS CURTAS EM DESBASTE NA REGIÃO DO NORTE PIONEIRO DO PARANÁ
}

\footnotetext{
Josenir Rodrigues de Ramos ${ }^{1}$, Rafael Oliveira Brown ${ }^{2}$, Lukas Kuhn Schuster ${ }^{3}$, Nelson Yoshihiro Nakajima ${ }^{4}$, Renato Cesar Gonçalves Robert ${ }^{4}$

${ }^{1}$ Engenheiro Industrial Madeireiro - Sudati - (lamec.ufpr@gmail.com)

${ }^{2}$ Mestrando em Engenharia Florestal, Laboratório de Abastecimento e Mecanização Florestal, Universidade Federal do Paraná-

${ }^{3}$ Bolsista de Extensão Universitária - Laboratório de Abastecimento e Mecanização Florestal, Universidade Federal do Paraná

${ }^{4}$ Eng. Florestal, Doutor em Engenharia Florestal, Professor da Universidade Federal do Paraná
}

Recebido em: 08/04/2016 - Aprovado em: 30/05/2016 - Publicado em: 20/06/2016 DOI: 10.18677/Enciclopedia_Biosfera_2016_153

\begin{abstract}
O presente estudo foi realizado no município de Ibaiti, Norte Pioneiro no Estado do Paraná, com o objetivo principal de analisar tecnicamente as etapas da colheita florestal mecanizada em desbaste de Pinus taeda correspondentes à derrubada, ao processamento, ao baldeio e ao carregamento. Para a análise técnica, foram analisadas: a produtividade florestal por hora efetiva de trabalho e os tempos dos ciclos operacionais de cada máquina estudada. Foram analisadas cinco parcelas, cada parcela com $1000 \mathrm{~m}^{2}$, totalizando 1025 covas, com um índice de sobrevivência médio de $85,4 \%$. O tempo médio do harvester por árvore foi 39,5 segundos. $A$ atividade que demandou maior tempo do ciclo operacional foi o desgalhamento, 0 qual utilizou $45,3 \%$ do tempo do ciclo operacional. Em seguida, veio derrubada, traçamento e deslocamento da máquina, que utilizaram um tempo médio de $23,2 \%$, $18,6 \%, 13 \%$ respectivamente. A produtividade média foi de 91 árvores por hora efetiva de trabalho e $17,1 \mathrm{~m}^{3}$ por hora efetiva de trabalho. Para o forwarder, o carregamento, descarregamento, deslocamento carregado e deslocamento vazio que consumiram 42,8\%, 37,9\%, 8,9, 8,6\% do ciclo total de extração, respectivamente. A produtividade média ficou com $30,9 \mathrm{~m}^{3}$ de extração de madeira por hora trabalhada. Para o carregador florestal, o carregamento consumiu 78,3\%, do tempo do ciclo operacional e as manobras adicionais consumiram os $21,7 \%$ restantes. A produtividade média foi de 125,7 toneladas por hora efetiva de trabalho.
\end{abstract}

RESUMO PALAVRAS-CHAVE: Cut-to-lenght; Pinus taeda; Produtividade.

\section{TECHNICAL ANALYSIS OF A MECHANIZED HARVEST SYSTEM OF SHORT LOGS IN THINNING IN NORTH PIONEER REGION OF PARANÁ.}

\section{ABSTRACT}

This study was realized in the city of Ibaiti, north pioneer region of Paraná, with the main objective of technically analyze the steps of the mechanized forest harvesting in thinning of Pinus taeda corresponding to overthrow, processing, hauling and loading. 
For the technical analysis, the forest productivity was analyzed by effective work hour and the time of the operational cycles of each studied machine. Five forest plantation plots were analyzed, each plot with $1000 \mathrm{~m}^{2}$, totalizing 1025 pits, with an average surviving index of $85.4 \%$. The average time of the harvester per tree was 39.5 seconds. The activity which required higher operational cycle time was the delimbing, which used $45.3 \%$ of the operational cycle time. Then came the overthrow, bucking and machine displacement, that used an average time of $23.2 \%, 18.6 \%, 13 \%$ respectively. The average productivity was 91 trees per effective hour of work and $17.1 \mathrm{~m}^{3}$ per effective hour of work. To the forwarder, the loading, unloading, loaded displacement and empty displacement that consumed $42.8 \%, 37.9 \%, 8.9 \%$ and $8.6 \%$ of the total extraction cycle. The average productivity was of $30.9 \mathrm{~m}^{3}$ of wood extraction per hour worked. To the forest loader, the loading consumed $78.3 \%$ of the operational cycle time and the additional maneuvers consumed the $21.7 \%$ remaining. The average productivity was 125.7 tons per effective hour of work.

KEYWORDS: Cut-to-lenght; Pinus taeda; Productivity.

\section{INTRODUÇÃO}

A colheita e transporte florestal é considerada por MACHADO (2014) operações que representam $50 \%$ ou mais, do total dos custos finais da madeira posta na fábrica, já SCHETTINO et al. (2014) preconizam que para atender a uma crescente demanda, em um cenário onde a mão de obra é escassa, a competitividade do setor é crescente, as exigências dos mercados consumidores globalizados são cada vez maiores e a mecanização das atividades de produção de madeira tornou-se imperiosa para a sustentabilidade do negócio florestal. Isso desencadeia um aumento no rendimento das operações de colheita florestal, elevando a produtividade e contribuindo para o aumento na competitividade das empresas florestais (BRAMUCCI \& SEIXAS, 2002).

Para fins de certificação, fizeram-se necessárias melhorias no planejamento no setor florestal a fim de maximizar os retornos em geral (LEITE et al. 2014). Dentro da colheita encontra-se a atividade de corte, conceituada como a separação das árvores das cepas dos pontos de crescimento, nessa operação concentram-se o corte, derrubada, desgalhamento, traçamento e empilhamento (LEITE et al. 2014).

O sistema de toras curtas, ou "cut-to-lenght" dispõem atualmente no mercado com tratores específicos para as atividades realizadas nesse sistema, os principais são o trator florestal autocarregável, forwarder, e o trator florestal, harvester, ambos podendo vir com gancho de tração auxiliar. A capacidade produtiva desses equipamentos já é tema de estudos, existindo hoje em dia informações sobre a capacidade real desses tratores. Apesar disso, como a aquisição desses equipamentos exige um alto investimento, ainda sim é necessário realizar estudos para obtenção de informações para desenvolver técnicas que melhor aproveitem o desempenho operacional desses equipamentos (LOPES \& DINIZ, 2015).

Dentro do processo de colheita destacam-se as atividades de extração, atividade essa que segundo MACHADO (2014) consiste em transportar a madeira do local de corte até o carreador ou pátio intermediário. Essa operação pode ser o arraste, onde parte ou toda a tora encosta no chão. Baldeio onde a madeira é transportada sobre uma plataforma, forwarder, sem contato com o chão e cabos aéreos. Ainda segundo o mesmo autor esse tipo de operação é um ponto crítico e exige um planejamento, para que sejam empregadas as técnicas e equipamentos de 
acordo com o sistema de colheita. Para esse planejamento alguns fatores influenciam tais como: densidade do talhão, topografia, tipo de solo, volume por árvore e distância.

Em países escandinavos e na Irlanda é amplamente difundido o sistema de colheita de toras curtas ou "cut-to-lenght" que é caracterizado pelo processamento da árvore no local de derrubada, essa atividade realizada de maneira mecanizada com o trator harvester ou semi-mecanizado com a motosserra. O baldeio é realizado posterior a essa operação com o uso do trator forwarder (FERNANDES et al., 2013). As vantagens de acordo com MACHADO (2014) são: baixa compactação do solo, facilita a locomoção, diminui os danos ao povoamento residual, demanda menor espaço de estoque de madeira na beira da estrada, não há necessidade da criação de trilhas de arraste e os equipamentos trabalham bem em áreas mais úmidas e com solos sensíveis. Este trabalho tem como objetivo analisar tecnicamente a colheita florestal mecanizada com o uso do sistema de toras curtas em desbaste no povoamento de Pinus taeda na região Norte Pioneiro do Paraná.

Com base nisso esse artigo objetivou realizar uma análise técnica de dois tratores florestais, forwarder e harvester na realização do desbaste em um plantio de Pinus taeda na região Norte Pioneiro do Estado do Paraná. Para isso foram realizados estudos de tempo e movimento e cálculo da produtividade desses equipamentos.

\section{MATERIAL E MÉTODOS}

O estudo foi conduzido em povoamentos de Pinus taeda de 11 anos de idade em uma propriedade localizada no município de Ibaiti, na região Norte Pioneiro do Estado do Paraná, entre as coordenadas UTM (DATUM SAD-69 - Fuso 22): norte= $7.348 .213 \mathrm{~m}$; leste $=583.685 \mathrm{~m}$. O relevo da propriedade é suave ondulado com altitude de 850, a classificação climática, segundo Köppen, é o tipo Cfa - subtropical úmido, mesotérmico, com verões quentes e com geadas pouco frequentes, e a temperatura média anual do município situa-se entre $21^{\circ} \mathrm{C}$ e $2^{\circ} \mathrm{C}$.

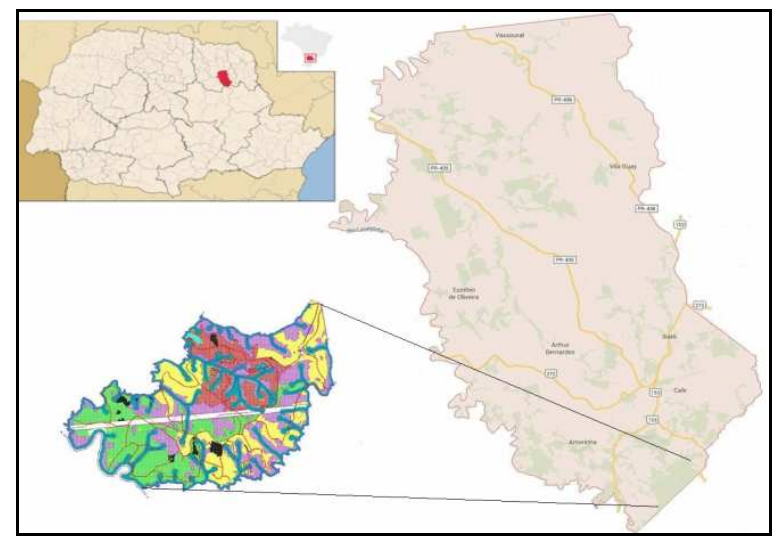

FIGURA 1 - Mapa de localização da área de estudo em Ibaiti - PR. Fonte: Os autores (2015).

O povoamento foi implantado em 2004, no espaçamento de 2,5 x 2,5 metros. De acordo com os dados de inventário florestal, fornecido pela empresa proprietária da fazenda, a densidade é de 1276 árvores por hectares, o diâmetro a altura do peito (DAP) médio é 23,2 centímetros, a altura média $15,7 \mathrm{~m}$, volume médio com casca das árvores é de $0,25 \mathrm{~m}^{3}$ e o volume médio por hectare é de $325,3\left(\mathrm{~m}^{3} \mathrm{ha}^{-1}\right)$. 
A colheita florestal foi realizada a partir de um desbaste misto, totalmente mecanizado, retirando a $5^{\text {a }}$ (quinta) linha de plantio (desbaste sistemático) e $30 \%$ das árvores remanescentes (desbaste seletivo), retirando principalmente as árvores suprimidas, tortuosas ou bifurcadas, já marcadas anteriormente no povoamento florestal pela equipe da empresa proprietária da fazenda (Figura 2).

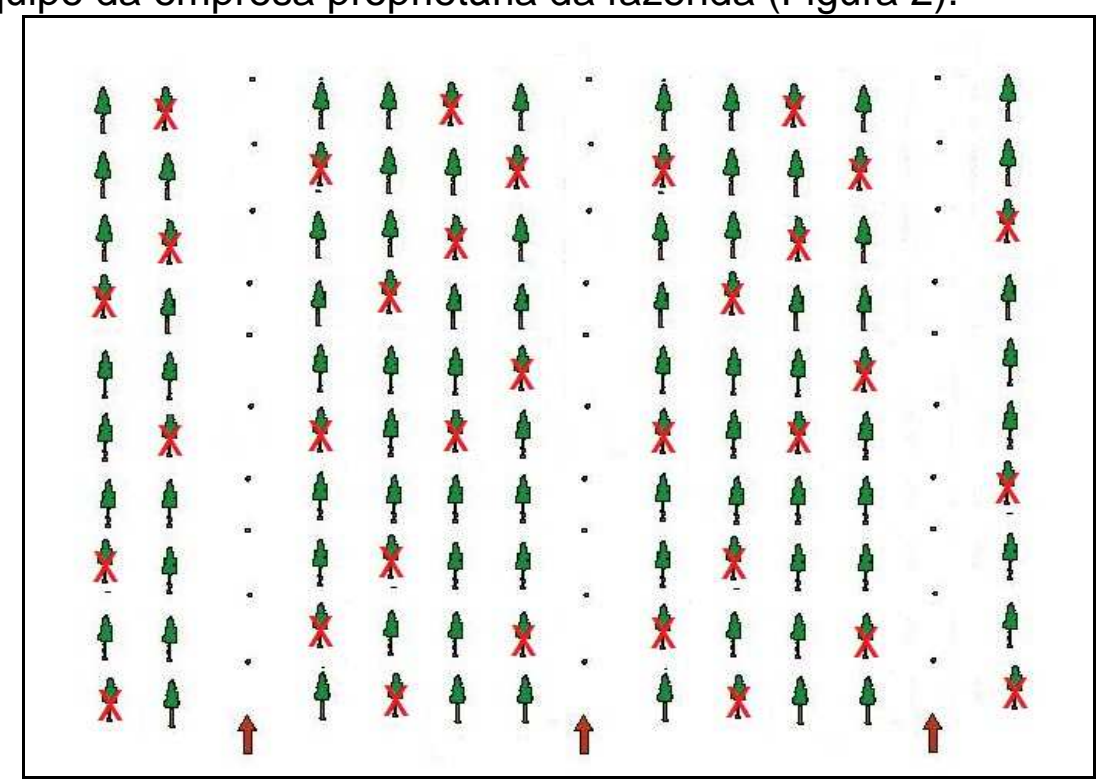

FIGURA 2 - Esquema ilustrativo do desbaste misto na área estudada. Fonte: Os autores (2015).

Foi avaliado um sistema de toras curtas (cut-to-length), composto por um módulo - base de três máquinas, descrito no Quadro 1.

QUADRO 1 - Descrição técnica das máquinas analisadas

\begin{tabular}{ccl}
\hline Trator florestal & \multicolumn{1}{c}{ Modelo } & \multicolumn{1}{c}{ Descrição } \\
\hline Harvester & CAT 320D FM & $\begin{array}{l}\text { Escavadeira florestal com rodados de esteiras, motor } \\
\text { de } 117 \mathrm{~kW} \text {. Cabeçote processador Log Max 6000B. }\end{array}$ \\
\hline Forwarder & CAT 584 & $\begin{array}{l}\text { Trator florestal com rodados de pneus, motor de 204 } \\
\mathrm{kW} . \text { Grua Epsilon X120F, com alcance de } 8,0 \mathrm{~m}, \\
\text { garra Epsilon FG37, capacidade de carga 18.000 kg. }\end{array}$ \\
\hline $\begin{array}{c}\text { Carregador } \\
\text { florestal }\end{array}$ & CAT 320D & $\begin{array}{l}\text { Escavadeira florestal com rodados de esteiras, motor } \\
\text { de } 117 \mathrm{~kW}, \text { garra Hultdins. }\end{array}$ \\
\hline
\end{tabular}

Fonte: Os autores (2015).

O trabalho foi compreendido de duas etapas básicas. Primeiramente, determinou-se a produtividade florestal, por hora efetivamente trabalhada das três máquinas que operam na colheita florestal, utilizando o volume de madeira e o número de árvores colhidas por hora efetiva de trabalho dentro de cada parcela. Logo após houve um acompanhamento seguido de uma coleta de dados dos elementos do ciclo operacional através do estudo de tempos e movimentos das máquinas na execução das operações de colheita da madeira, sendo o ciclo operacional de cada máquina subdividida em elementos parciais.

No estudo de tempos e movimentos do ciclo operacional do harvester, obtiveram-se os tempos parciais: corte (CT) - inicia-se com o acionamento do sabre de corte até a manobra de derrubada; desgalhamento (DG) - árvore em posição horizontal com sabre desativado e rolos e facas acionadas; traçamento (TÇ) - a 
partir da medição inicial ao traçamento da última tora e deslocamento da máquina (DM) - deslocamento da máquina dentro da linha de plantio, na parcela.

O ciclo operacional do forwarder foi composto pelos seguintes tempos parciais: deslocamento vazio (DV) - iniciava com o deslocamento da máquina da beira do talhão e terminava com o posicionamento próximo à primeira pilha de toras a ser carregada na parcela; carregamento (CR) - iniciava com o deslocamento da grua de carregamento após o posicionamento da máquina, e finalizava, quando a caixa de carga da máquina estava completa com a grua posicionada sobre as toras, incluindo os tempos de deslocamentos entre as pilhas de toras na parcela; deslocamento carregado (DC) - iniciava com o posicionamento da grua sobre a caixa de carga e finalizava com o posicionamento da máquina próximo à pilha de toras na beira do talhão com início da movimentação da grua; descarregamento (DT) - iniciava com a movimentação da grua para realizar o descarregamento das toras e finalizava com o posicionamento da grua sobre a caixa de carga da máquina vazia.

Para o forwader, foram avaliadas as seguintes atividades parciais: carregamento (CG) - iniciava com o posicionamento da máquina entre a pilha de madeira e o veículo transportador, deslocamento da grua carregada, arrumação da carga e finalizava, com o carregamento total do veículo de transporte; manobras adicionais (MA) - iniciava com os deslocamentos adicionais necessários para executar o carregamento do veículo.

As atividades executadas na colheita na fazenda eram realizadas em uma jornada de trabalho de 24 horas, distribuídas em três turnos ( 7 às 15 horas, 15 às 23 horas e 23 às 7 horas) com um horário de refeição de uma hora por turno. Cada máquina era operada por três operadores, sendo um por turno. Para a coleta de dados deste estudo, foram realizadas as medições apenas no turno das 7 às 15 horas com um único operador.

Segundo a metodologia proposta por BARNES (1977) primeiramente foi feito um estudo piloto, para inferir estatisticamente sobre as operações. Foi definido o número mínimo de observações necessárias no ciclo operacional em cada fase do ciclo de trabalho, a fim de proporcionar um erro de amostragem máximo de $10 \%$ (Equação 1).

$$
\mathrm{n} \geq \frac{\mathrm{t}^{2}+C V^{2}}{\mathrm{E}^{2}}
$$

Sendo:

$\mathrm{n}$ = número mínimo de ciclos necessários;

$\mathrm{t}=$ valor de $\mathrm{t}$, para o nível de probabilidade desejado $(\mathrm{n}-1)$ graus de liberdade;

$\mathrm{CV}=$ coeficiente de variação, em porcentagem e;

$E=$ erro admissível, em porcentagem (10\%).

A partir desse ponto, foram preliminarmente selecionadas, dentro de um talhão de 18,5 hectares, cinco parcelas de cinco linhas de plantio cada, contendo 41 covas. A área total de cada parcela foi de $1000 \mathrm{~m}^{2}$, ou seja, 0,10 ha, com dimensões de $10 \mathrm{~m}$ de largura por $100 \mathrm{~m}$ de comprimento. A soma das parcelas totalizou 5000 $\mathrm{m}^{2}$ de povoamento florestal. Procurou-se alocar as parcelas de forma que as condições de terreno, declividade, padrão da floresta, entre outras, fossem as mais homogêneas possíveis. 
O harvester utilizado nesta etapa é composto de uma escavadeira florestal com esteiras CAT 320D FM e um cabeçote processador Log Max 6000B (Figura 3).

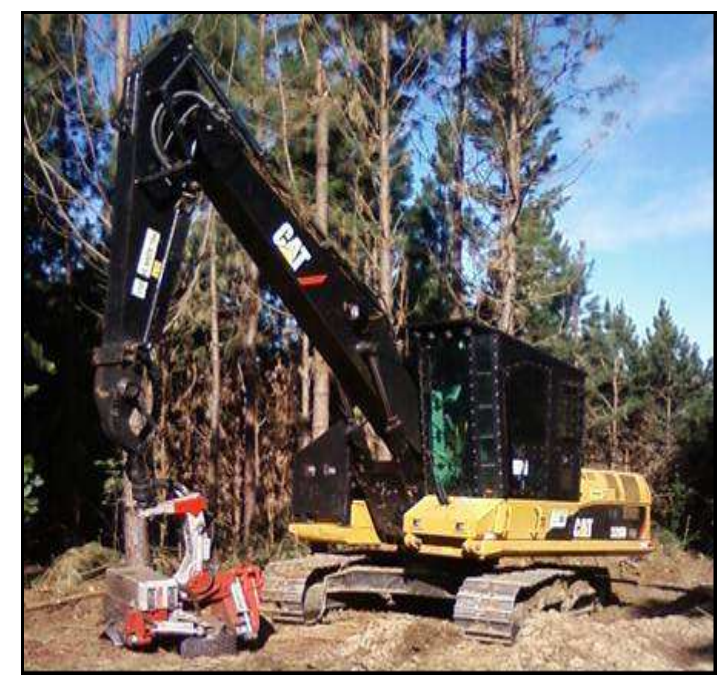

FIGURA 3 - Harvester usado no estudo.

Fonte: Os autores (2015).

As toras foram cortadas com $3,60 \mathrm{~m}$ de comprimento, com um diâmetro mínimo de $8 \mathrm{~cm}$ na ponta mais fina e até um diâmetro máximo de $40 \mathrm{~cm}$ na ponta mais grossa, segundo especificações técnicas do fabricante. O cabeçote tem capacidade de processar toras com diâmetros mínimo de $3 \mathrm{~cm}$ na ponta mais fina até $62,5 \mathrm{~cm}$ na ponta mais grossa.

O eito de trabalho (parcela) era composto de cinco fileiras de árvores, onde o harvester colhia primeiro as árvores da linha do centro e depois as árvores marcadas nas duas linhas remanescentes de cada lado. A madeira, após o processamento, era depositada à esquerda do sentido de deslocamento da máquina, entre as árvores remanescentes. A máquina utilizada para realizar a extração (baldeio das toras) foi um forwarder CAT 584. Essa máquina tem a finalidade de promover o carregamento da madeira (toretes) dentro da linha de desbaste sistemático e o descarregamento nas margens das estradas ou pátios temporários.

As parcelas onde ocorreu o desbaste foram alocadas próximas às estradas principais do talhão na propriedade, implicando na diminuição da distância média de transporte (baldeio). O carregador utilizado nesta etapa é também uma máquina de esteiras Escavadeira Florestal CAT 320D como mostra a figura 4. Houve a substituição do compartimento de carga na extremidade do braço por uma garra. 


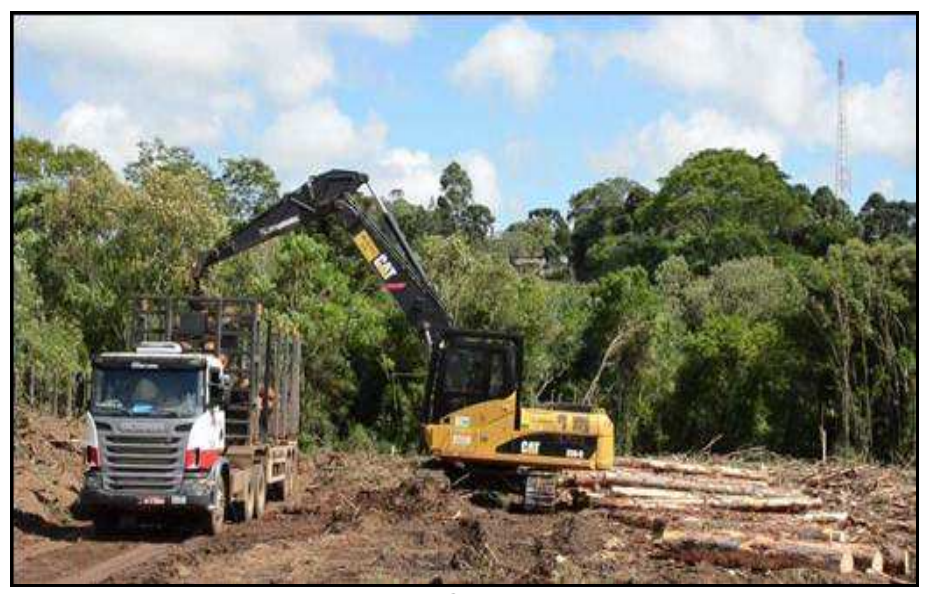

FIGURA 4 - Detalhes do Carregador Florestal.

Fonte: www.siqueiraflorestal.com.br (2015).

A determinação da produtividade para o harvester foi levantada baseada na metodologia de SILVA et al., (2010) utilizando o volume de madeira e o número de árvores colhidas por hora efetiva de trabalho. $O$ tempo gasto para cada parcela ser processada pelo harvester foi cronometrado, o início do cronômetro coincidia no momento que o cabeçote era posicionado na primeira árvore, o tempo era encerrado após o processamento da última árvore daquela parcela. Ao início de cada parcela havia uma pausa de aproximadamente 60 segundos, esse tempo era despendido na ativação do contador de volume instalado no computador do harvester. O contador de volume é capaz de guardar informações como o número de árvores processadas, volume processado entre outros. Por meio do uso desse software foi possível coletar dados do volume com casca, e número de árvores colhidas em cada parcela, permitindo calcular o volume e número de árvores cortadas por hora efetivamente trabalhadas em cada parcela.

A determinação da produtividade do forwarder foi obtida por meio do volume processado pelo harvester em cada parcela, que posteriormente foi dividido pelas horas efetivamente trabalhadas, conforme descrita na equação 2.

$$
P f=\frac{V p}{h e}
$$

Sendo:

$\mathrm{Pf}=$ produtividade forwarder $\left(\mathrm{m}^{3} \mathrm{cc}\right.$ he $\left.{ }^{-1}\right)$

$\mathrm{Vp}=$ volume médio processado por parcela $\left(\mathrm{m}^{3} \mathrm{cc}\right)$

he $=$ horas efetivas de trabalho.

O carregador florestal teve a produtividade média calculada em toneladas por hora efetiva de trabalho, de acordo com a equação 3.

$$
\mathrm{Pr}=\frac{\mathrm{t}}{\mathrm{he}}
$$

Sendo:

$\operatorname{Pr}=$ produtividade $\left(\right.$ ton $\mathrm{e}^{-1}$ )

$\mathrm{t}=$ toneladas de madeira carregada (obtido através da balança da fábrica) 
he $=$ horas efetivamente trabalhadas.

\section{RESULTADOS E DISCUSSÃO}

O tempo médio para processamento das parcelas pelo harvester foi de 41,9 minutos, o tempo mínimo apresentado foi de 37,0 minutos e o máximo foi de 46,7 minutos. As parcelas analisadas apresentaram um volume médio de $11,9 \mathrm{~m}^{3}$, com base no volume fornecido pelo Log Mate 500. A Tabela 1 apresenta os dados das parcelas analisadas.

TABELA 1 - Dados das parcelas analisadas.

\begin{tabular}{|c|c|c|c|c|c|c|}
\hline \multirow[b]{2}{*}{ Parcelas } & \multirow[b]{2}{*}{ Área $\left(\mathrm{m}^{2}\right)$} & \multicolumn{3}{|c|}{ Árvores } & \multirow{2}{*}{$\begin{array}{c}\text { Vol. } \\
\text { Desb. } \\
\left(\mathrm{m}^{3}\right)\end{array}$} & \multirow{2}{*}{$\begin{array}{c}\text { Tempo/parcela } \\
\text { (min) }\end{array}$} \\
\hline & & №/parcela & $\begin{array}{l}\text { Extraídas } \\
\text { desbaste }\end{array}$ & Remanesc. & & \\
\hline Parcela 1 & 1000 & 175 & 60 & 115 & 11,1 & 39,5 \\
\hline Parcela 2 & 1000 & 190 & 71 & 119 & 13,3 & 46,7 \\
\hline Parcela 3 & 1000 & 146 & 61 & 85 & 11,6 & 40,0 \\
\hline Parcela 4 & 1000 & 164 & 56 & 108 & 10,4 & 37,0 \\
\hline \multirow[t]{3}{*}{ Parcela 5} & 1000 & 200 & 71 & 129 & 13,3 & 46,5 \\
\hline & Soma & 875 & 319 & 556 & 59,7 & 209,7 \\
\hline & Média & - & - & - & 11,9 & 41,94 \\
\hline
\end{tabular}

Fonte: Os autores (2015).

O volume médio individual das árvores retiradas no desbaste misto ficou com 0,19 metros cúbicos com casca $\left(\mathrm{m}^{3} \mathrm{cc}\right)$, devido ao número de árvores suprimidas, tortuosas ou bifurcadas no desbaste seletivo. O volume médio das parcelas ficou em $59,7 \mathrm{~m}^{3}$, o que totaliza aproximadamente $119,40 \mathrm{~m}^{3} / \mathrm{ha}$.

\section{Análise do ciclo operacional e da produtividade do Harvester}

Com base no estudo de tempo e movimento foi possível determinar o percentual parcial gasto em cada atividade, através da coleta de 495 ciclos operacionais do harvester, tomando como base algumas árvores escolhidas aleatoriamente dentro de cada parcela, de maneira a encontrar os tempos médios dos ciclos operacionais. O tempo médio do harvester por árvore foi 39,5 segundos.

A atividade que demandou maior tempo do ciclo operacional do harvester foi o desgalhamento (DG), o qual utilizou $45,3 \%$ do tempo do ciclo operacional, correspondente a um tempo médio de 17,9 segundos por árvore. A seguir veio o corte (CT) que utilizou um tempo médio de 9,2 segundos, equivalendo a $23,2 \%$. $O$ traçamento (TC), absorvendo em média 7,3 segundos do ciclo operacional, consumindo $18,6 \%$. Logo após, veio o deslocamento da máquina (DM) que consumindo em média 5,1 segundos, igual a $13,0 \%$ do tempo total. A Figura 5 apresenta a média geral do percentual de tempo em cada etapa do processamento das árvores. 


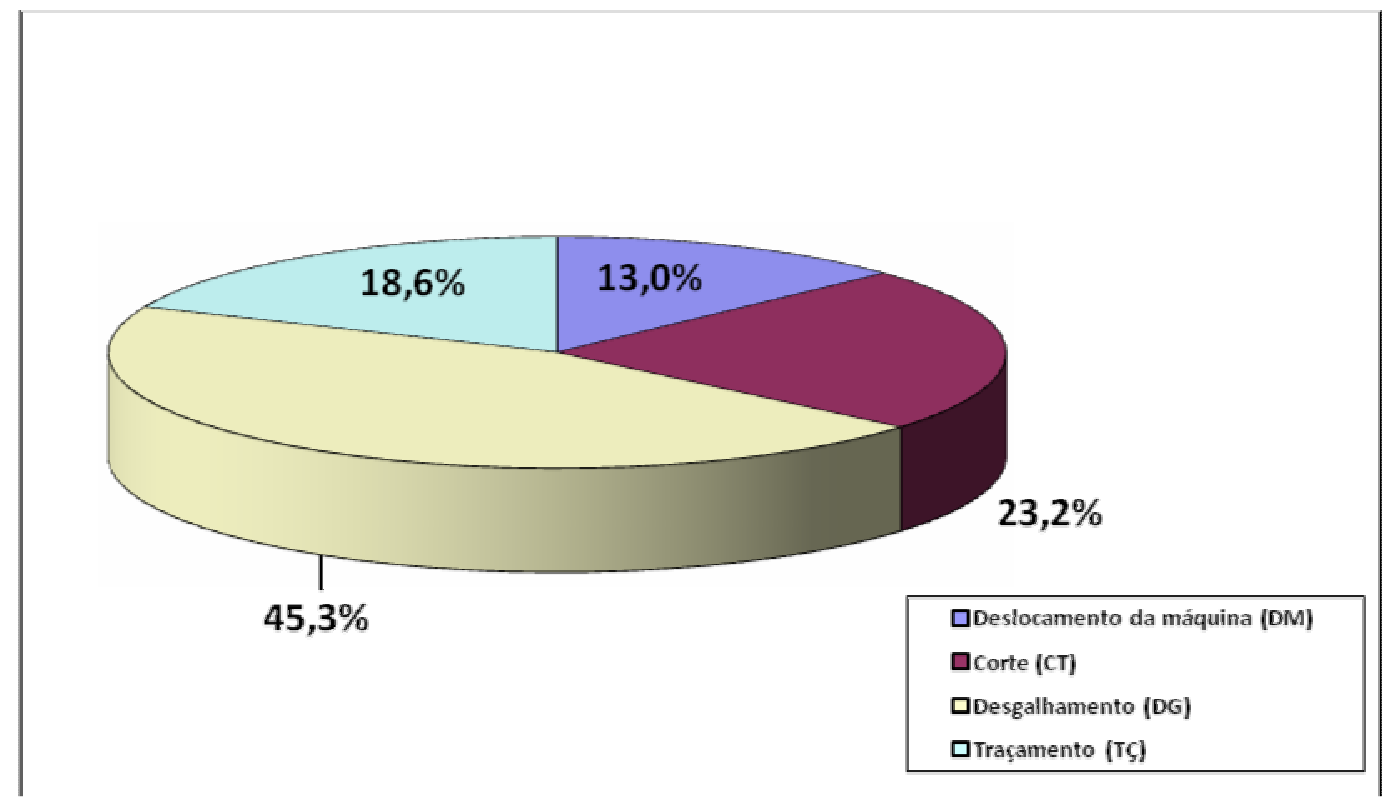

FIGURA 5 - Elementos do ciclo operacional do Harvester.

Fonte: Os autores (2015).

O maior tempo consumido no desgalhamento (DG) das árvores $(45,3 \%$ do tempo do ciclo operacional) pode ser explicado pela falta de desrama no talhão, além do fato que o Pinus taeda apresentar galhos em maior quantidade, mais grossos. DRINKO et al. (2015) obtiveram em suas avaliações na etapa de processamento (envolvendo as atividades de desgalhamento, destopamento e traçamento), 49,0\%, do tempo para harvester de pneus e 43\% para harvester de esteira para o ciclo operacional do harvester em colheita de Pinus taeda, ficando próximo com os valores encontrados na presente análise. SILVA et al., (2010) no entanto encontraram valores superiores, $66 \%$ do tempo do ciclo de harvester foi usado para o processamento da árvore.

Em trabalho realizado em um povoamento de Eucalyptus grandis, num sistema de toras longas, LOPES et al. (2011) avaliaram tecnicamente os equipamentos, harvester e forwarder. No estudo de tempos e movimentos 0 harvester $46 \%$ do tempo foi despedido no ciclo de corte, seguido com interrupções com $36 \%$. O tempo gasto com o ciclo de corte é justificado uma vez que esse agrupa diversas tarefas como corte, tombamento, desgalhamento, descascamento e traçamento.

FERNANDES et al. (2013) encontraram resultados um pouco superiores em estudo com Eucalyptus grandis, $70 \%$ do tempo foi gasto no ciclo de corte, $29 \%$ gastos em descascamento, $23 \%$ em traçamento, $10 \%$ em tombamento e $8 \%$ no corte. LEITE et al. (2014) em trabalho avaliando harvester em plantios de Eucalyptus grandis encontraram que o traçamento foi a atividade que despendeu maior tempo, $47 \%$, seguidos do posicionamento do cabeçote e descascamento/desgalhamento com $17 \%$ e $14 \%$ respectivamente. Em outro trabalho realizado com tempo e movimento em um povoamento de Eucalyptus grandis, num sistema de colheita de toras curtas, SIMÕES \& FENNER (2010), acharam valores próximos, sendo $62,59 \%$ gastos com o ciclo de corte.

A produtividade média das parcelas analisadas apresentou um volume médio $11,9 \mathrm{~m}^{3}$, com base no volume fornecido pelo Log Mate 500. O rendimento médio do harvester foi de 91 árvores por hora efetiva de trabalho produzindo $17,1 \mathrm{~m}^{3}$ de ENCICLOPÉDIA BIOSFERA, Centro Científico Conhecer - Goiânia, v.13 n.23; p.1772 
madeira com casca por hora trabalhada na colheita do desbaste misto. Comparando com a avaliação de LOPES et al. (2013), a produtividade efetiva de trabalho de 17,1 $\mathrm{m}^{3} / \mathrm{h}$ pode ser considerada boa, por se tratar de $1^{\circ}$ desbaste, e também pelo diâmetro médio das árvores ser de $0,19 \mathrm{~m}^{3}$, contra $0,49 \mathrm{~m}^{3}$ encontrado na avaliação dos autores.

\section{Análise do ciclo operacional e da produtividade do Forwarder}

O tempo médio do forwarder por parcela foi de 1388,6 segundos, ou seja, 23,1 minutos, percorrendo uma distância média de extração de 100 metros. Na Tabela 2 são apresentados os tempos dos ciclos operacionais.

TABELA 2 - Dados do ciclo operacional e produtividade do forwarder.

\begin{tabular}{|c|c|c|c|c|c|c|}
\hline \multirow[b]{2}{*}{ Parcelas } & \multirow[b]{2}{*}{ DV } & \multicolumn{3}{|c|}{ Ciclos Operacionais (segundos) } & \multirow[t]{2}{*}{$\begin{array}{c}\text { Tempo } \\
\text { (seg.) }\end{array}$} & \multirow[t]{2}{*}{$\begin{array}{l}\text { Produtividade } \\
\text { (m³/parcela) }\end{array}$} \\
\hline & & CR & DC & DT & & \\
\hline Parcela 1 & 116,2 & 556,3 & 122,7 & 528,6 & 1323,8 & 11,1 \\
\hline Parcela 2 & 128,8 & 634,1 & 129,4 & 605,3 & 1497,6 & 13,3 \\
\hline Parcela 3 & 113,2 & 588,6 & 116,3 & 533,4 & 1351,5 & 11,6 \\
\hline Parcela 4 & 109,8 & 534,8 & 113,2 & 490,2 & 1248,0 & 10,4 \\
\hline Parcela 5 & 132,4 & 655,5 & 132,8 & 601,5 & 1522,2 & 13,3 \\
\hline Soma & 600,4 & 2969,3 & 614,4 & 2759,0 & 6943,1 & 59,7 \\
\hline Média & 120,1 & 593,9 & 122,9 & 551,8 & 1388,6 & 11,9 \\
\hline
\end{tabular}

Fonte: Os autores (2015).

Sendo:

$\mathrm{DV}=$ deslocamento vazio

$\mathrm{CR}=$ carregamento

$\mathrm{DC}=$ deslocamento carregado

DT $=$ descarregamento.

Como pode ser observado, o carregamento dos toretes (CR) consumiu a maior parte do tempo total do ciclo operacional (593,9 segundos), gastando $42,8 \%$ do tempo do ciclo operacional. Em seguida, ficou o descarregamento dos toretes (DT) na beira das estradas do talhão com 551,8 segundos, consumindo $37,9 \%$ do ciclo operacional. O elemento deslocamento carregado (DC), consumiu 122,9 segundos, equivalendo a $8,9 \%$, do tempo. O elemento que consumiu menos tempo do ciclo operacional foi o deslocamento vazio, 120,1 segundos, correspondendo a $8,6 \%$ do ciclo total de extração. A Figura 6 apresenta a média geral do percentual de tempo em cada etapa da extração das toras das parcelas. 


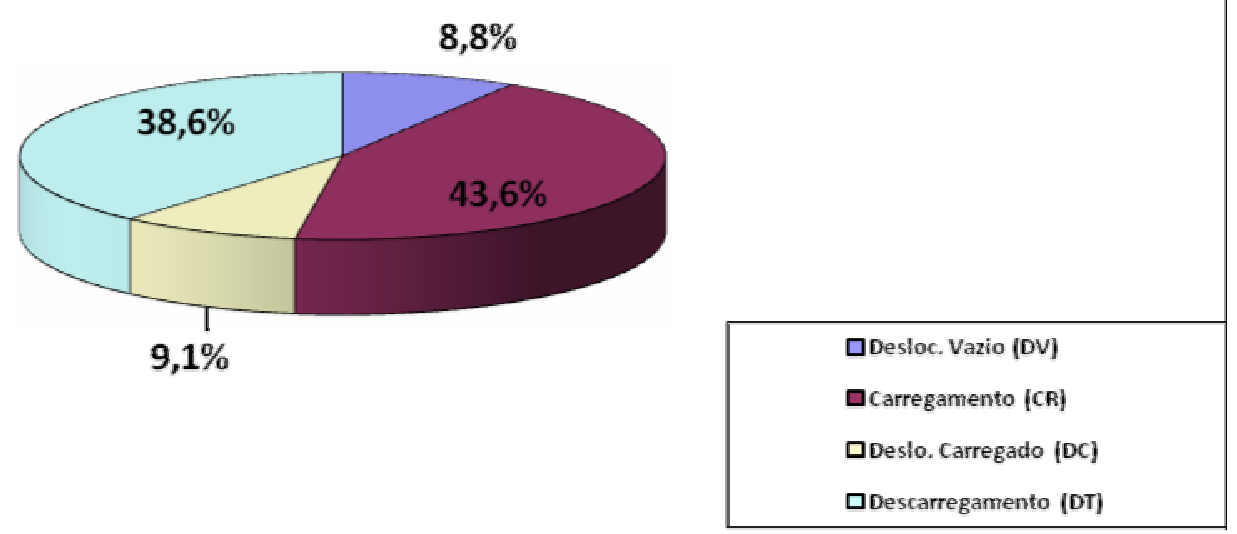

FIGURA 6 - Porcentagem dos elementos do ciclo operacional do forwarder Fonte: Os autores (2015).

De acordo com a análise operacional do forwarder na extração de toras de pinus em regime de desbaste, descrita por LOPES \& DINIZ (2015) o elemento que consumiu o maior tempo percentual foi o carregamento das toras, com 52 e $50 \%$ do tempo total, atribuindo o elevado tempo consumido pelo baixo volume de madeira produzida pelo desbaste, cujas pilhas de toras são normalmente de baixo volume e com maior distância entre si ao longo da linha de extração. De acordo com SIMÕES \& FENNER (2010) na análise técnica de forwarder na extração de toras de pinus, o carregamento e descarregamento consumiram $78,4 \%$ do tempo total. $O$ elevado tempo de carregamento ocorreu devido ao excesso de deslocamentos da máquina no interior do talhão para efetuar o carregamento de toras com diferentes sortimentos.

Em relação ao forwarder, LOPES et al. (2011) encontraram resultados no estudo de tempo e movimentos no qual $25 \%$ do tempo foi gasto com carregamento, descarregamento, $20 \%$, com $15 \%$ e $14 \%$ ficaram as viagens descarregadas e carregadas respectivamente, as interrupções ficaram com $26 \%$ do tempo total. A produtividade média do forwarder por hora efetiva de trabalho totalizou 1388,6 segundos, o que corresponde à produtividade média de $30,9 \mathrm{~m}^{3}$ de madeira extraída por hora trabalhada.

\section{Análise dos elementos do ciclo operacional e da produtividade do Carregador Florestal}

Com base no estudo de tempo e movimento, foi possível determinar o percentual parcial gasto em cada atividade, através da coleta de 18 ciclos operacionais do carregador florestal. O tempo médio do carregamento foi de 1176,0 segundos, ou seja, 19,6 minutos por caminhão. O elemento que gastou mais tempo foi o carregamento dos toretes no caminhão (CG), consumindo 920,8 segundos $(78,3 \%)$, seguido pelas manobras adicionais (MA) que consumiram 255,2 segundos $(21,7 \%)$ do tempo do ciclo operacional. A Figura 7 apresenta a média geral do percentual de tempo em cada etapa do carregamento dos caminhões. 


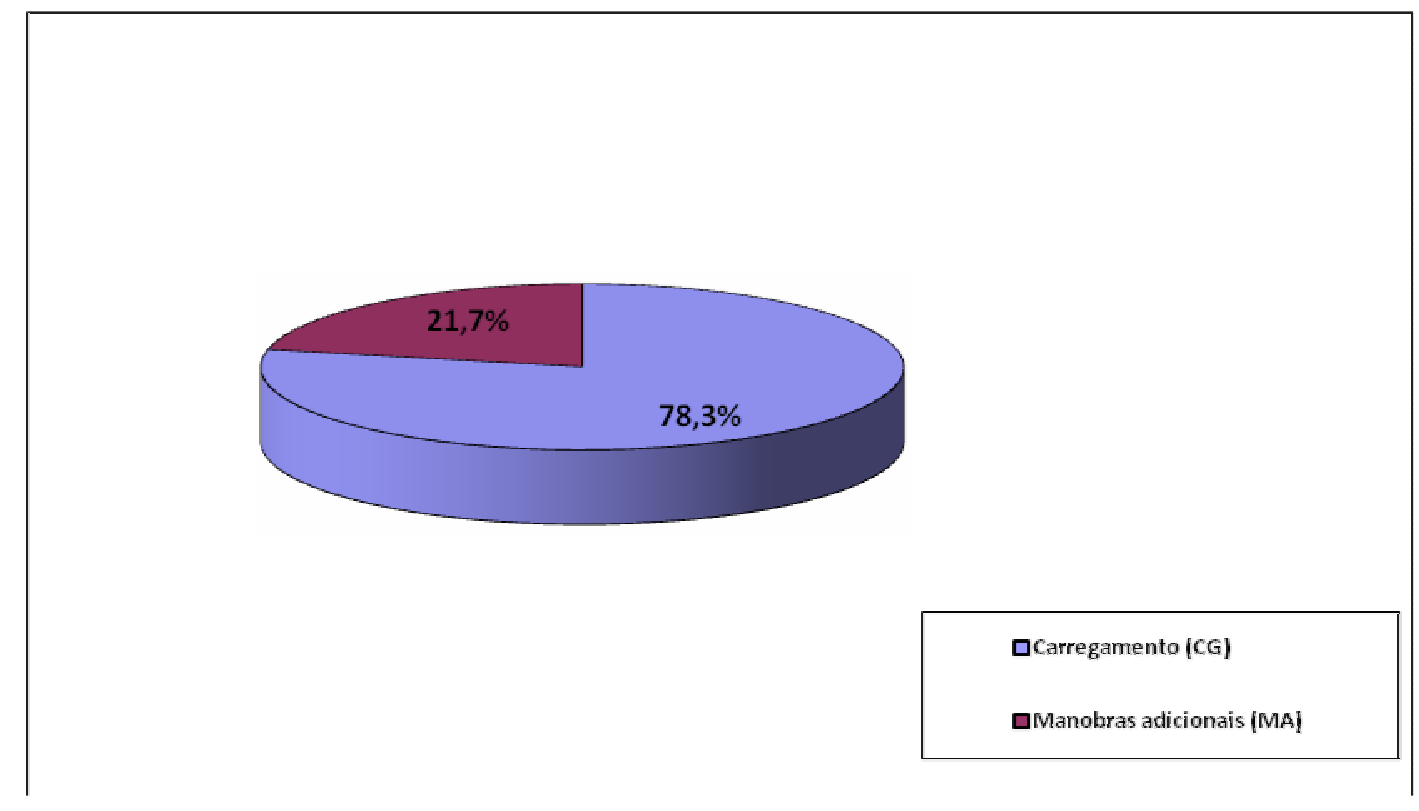

FIGURA 7 - Porcentagem de tempo dos elementos do ciclo operacional do Carregador Florestal

Fonte: Os autores (2015).

O tempo gasto pelo carregador florestal foi de 19,6 minutos, acarretando uma produtividade média de 125,7 toneladas por hora efetiva de trabalho. Foi usado nesse carregamento, para a coleta dos ciclos operacionais apenas a madeira oriunda das parcelas dessa análise, que estava baldeada na margem da estrada principal do talhão. Entre os principais fatores que influenciam no rendimento do carregamento, estão a capacidade da grua, comprimento dos toretes, volume do feixe, organização do estaleiro.

\section{CONCLUSÕES}

O estudo concluiu que o harvester em seu ciclo operacional obteve resultados próximos dos encontrados em estudos de tempo e movimento quando utilizada na colheita da mesma espécie. A produtividade do harvester foi um pouco inferior ao encontrado em outros estudos, justificado pelo motivo de ser o primeiro desbaste com árvores de menor volume.

Já o forwarder nesse estudo passou maior parte do tempo se deslocando, a despeito de outros estudos onde o equipamento passou mais tempo no carregamento de toretes. A produtividade do forwarder foi comprometida pelo baixo volume do feite de madeira, em decorrência do baixo volume individual.

\section{REFERÊNCIAS}

BARNES, R. M. Estudos de movimentos e de tempos: projeto e medida do trabalho. 6. ed. São Paulo: Edgard Blucher, 1977. 635p. 
BRAMUCCI, M.; SEIXAS, F. Determinação e quantificação de fatores de influência sobre a produtividade de "harvesters" na colheita florestal. Scientia Forestalis, n.62, p.62-74, 2002. Disponível em: http://www.ipef.br/publicacoes/scientia/nr62/cap06.pdf

DRINKO, C. H.; LOPES E. S.; OLIVEIRA F. M. Produtividade e custos do corte de pinus com harvester de pneus e esteiras, Enciclopédia Biosfera, Centro Científico Conhecer- Goiânia,v.11n.22;p. $2015 . \quad$ Disponível em: http://www.conhecer.org.br/enciclop/2015c/agrarias/Produtividade\%20e\%20Custo.pd f. DOI: <http://dx.doi.org/10.18677/Enciclopedia_Biosfera_2015_254>

FERNANDES, H. C.; BURLA, R. E.; LEITE, E. S.; MINETTE, L. J. Avaliação técnica e econômica de um "Harvester" em diferentes condições de terreno e produtividade da Floresta, Scientia Forestalis., Piracicaba, v. 41, n. 97, p. 145-151, mar. 2013. Disponível em: http://ipef.br/publicacoes/scientia/nr97/cap15.pdf

LEITE, E. S.; MINETTE, L. J.; FERNANDES, H. C.; SOUZA, A. P; AMARAL, do E. J.; LACERDA; E. G. Desempenho do harvester na colheita de eucalipto em diferentes espaçamentos e declividades. Revista Árvore, Viçosa-MG, v.38, n.1, p.000-000, 2014. Disponível em: http://www.scielo.br/pdf/rarv/v38n1/09.pdf DOI: < http://dx.doi.org/10.1590/S0100-67622014000100009>

LOPES, E. S.; RODRIGUES, C. K.; CARMO, F. C.; FIEDLER, N. C.; OLIVEIRA, D.; Avaliação técnica e de custos de um sistema de cabos aéreos na extração de Pinus taeda L. em região montanhosa. Scientia Forestalis, Piracicaba, v. 39, n. 91, p. 387- 394, 2011. Disponível em: http://www.ipef.br/publicacoes/scientia/nr91/cap11.pdf

LOPES, E. S.; RUDEK A.; OLIVEIRA D., GONÇALVES. S. B. Influência da distância de guinchamento e de extração na produtividade de um sistema de cabos aéreos em região montanhosa. Enciclopédia Biosfera, Goiânia, v. 9, n. 17, p. 1696-1704, 2013.

Disponível

em:

http://www.conhecer.org.br/enciclop/2013b/CIENCIAS\%20AGRARIAS/influencia\%20 da\%20distancia.pdf

LOPES, E. S.; DINIZ, C. C. C. Produtividade do trator florestal chocker skidder na extração de madeira em terrenos declivosos. Floresta, Curitiba, PR, v. 45, n. 3, p. 625 - 634, jul. / set. 2015. Disponível em: http://ojs.c3sl.ufpr.br/ojs/index.php/floresta/article/viewFile/36409/26329. doi: <http://dx.doi.org/10.5380/rf.v45i3.36409>

MACHADO, C. C. Colheita florestal. 3a ed. Viçosa, MG, Ed. UFV, 2014.

SCHETTINO S.; MINETTE, L. J.; SOUZA A. P. Correlação entre volumetria de florestas de eucalipto e produtividade e custos de máquinas de colheita de madeira. Revista Árvore, Viçosa-MG, v.39, n.5, p.935-942, 2015. Disponível em: http://www.scielo.br/pdf/rarv/v39n5/0100-6762-rarv-39-05-0935.pdf. DOI: < http://dx.doi.org/10.1590/0100-67622015000500016 >

SILVA, E. N.; MACHADO, C. C.; MINETTE, L. J.; SOUZA, A. P.; FERNANDES, H. C.; SILVA, M. L.; JACOVINE, L. A. Avaliação técnica e econômica do corte 
mecanizado de Pinus sp. com harvester. Revista Árvore, Viçosa-MG, v.34, n.4, p.745-753, 2010. Disponível em: http://www.scielo.br/pdf/rarv/v34n4/v34n4a19.pdf. DOI: <http://dx.doi.org/10.1590/S0100-67622010000400019>

SIMÕES, D.; FENNER, P. T. Avaliação técnica e econômica do forwarder na extração de madeira em povoamento de eucalipto de primeiro corte. Revista Floresta, v. 40, n. 4, p. 711-720. 2010. Disponível em: https://www.researchgate.net/profile/Paulo_Fenner/publication/228743880_AVALIAC AO_TECNICA_E_ECONOMICA_DO_FORWARDER_NA_EXTRACAO_DE_MADEI

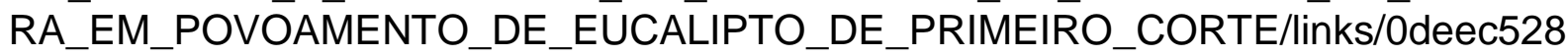
88f8b299f5000000.pdf. DOI: <http://dx.doi.org/10.5380/rf.v40i4.20323> 